\title{
Impact of COVID-19 on airline industry and strategic plan for its recovery with special reference to data analytics technology
}

\author{
Rajee Olaganathan * \\ Embry-Riddle Aeronautical University - Worldwide, USA. \\ Global Journal of Engineering and Technology Advances, 2021, 07(01), 033-046 \\ Publication history: Received on 26 February 2021; revised on 29 March 2021; accepted on 01 April 2021
}

Article DOI: https://doi.org/10.30574/gjeta.2021.7.1.0050

\begin{abstract}
This paper discusses the status quo of the airline industry around the world facing the COVID-19 pandemic situation. The purpose of the first part of this study was to assess the impact of COVID-19 on global air traffic, airline revenues by region of operation, number of international passengers by region, and the number of domestic passenger traffic by route group. The data for this study was collected from January 2019 to December 2020 from the International Civil Aviation Organization (ICAO) database. The research strategy of the second part of this study is based on PEST analysis which is applied to evaluate the current situation of the airline industry. Based on the findings, this paper suggests strategies and recommendations for the airline industry to adapt to the pandemic situation based on technology aspects more specifically related to data analytics with a multi-step approach for COVID-19 Airline Recovery Plan. The results and recommendations of this research study will provide valuable information to the aviation industry for its preparedness for the Post-COVID-19 era.
\end{abstract}

Keywords: COVID-19; Data Analytics; Airline Recovery Plan; Post-COVID-19 era; PEST Analysis; Airline Industry

\section{Introduction}

The COVID-19 pandemic outbreak that occurred in 2019 is still ongoing and posing a continuous threat to both the economy and public health at the global level [1]. It has disrupted business operations in all industries. One of the important sectors that contribute to the global economic growth which was affected by COVID-19 is the aviation industry. The aviation industry has contributed to 3.6 percent of the world's GDP by creating a total of 65.6 million jobs around the world in aviation-related industries through different types of jobs [2]. The direct job includes employment of aircrew, airport operators, airlines, air navigation service providers and indirect employment includes construction companies, fuel service providers, suppliers of original equipment manufacturers, and several others [3]. Among these 65.6 million jobs, approximately 36.7 million jobs come through the tourism industry in which air travel plays a significant role [2].

The present air transportation system has evolved over the past eight decades to fulfill the requirements of the growing social and economic demands for global connectivity and globalization [4]. The evolution of world passenger traffic from 1945 to 2020 was given in Fig.1. Commercial air travel alone contributes to approximately 3.5 billion trips per year and more than forty percent of this accounts for international trips [5]. Thus air transportation plays an essential role in carrying passengers and goods across the country and contributed to global economic growth. Apart from its vital role in international trade and global GDP growth the increased connectivity of air travel also expedites the geographic spread of infectious diseases.

\footnotetext{
${ }^{*}$ Corresponding author: Rajee Olaganathan

Embry-Riddle Aeronautical University - Worldwide, USA.
} 
The aviation industry is susceptible to external threats like recession, natural disasters, oil crises, and disease outbreaks. These threats severely affect global air travel by increasing flight cancellations, causing the grounding of aircraft, travel bans, and closure of international borders. The catastrophic shocks faced by the aviation industry and the decline in passenger traffic are illustrated in Fig.1. The most notable decrease in air traffic occurred during the oil crisis, Iran-Iraq war, Gulf crisis, Asian crisis [6], and September 11, 2001 attacks [7]. The most significant disease outbreak that affected the aviation industry before Covid-19 was SARS (Severe Acute Respiratory Syndrome) that occurred in 2003 [8]. Among the different crises that affected the aviation industry, the major disruptor has been disease outbreaks (Fig.1). The increased global connectivity has amplified the risk of disease introduction and its spread at the global level. The spread of the pathogen is influenced by the number of passengers, their place of origin, and their destination.

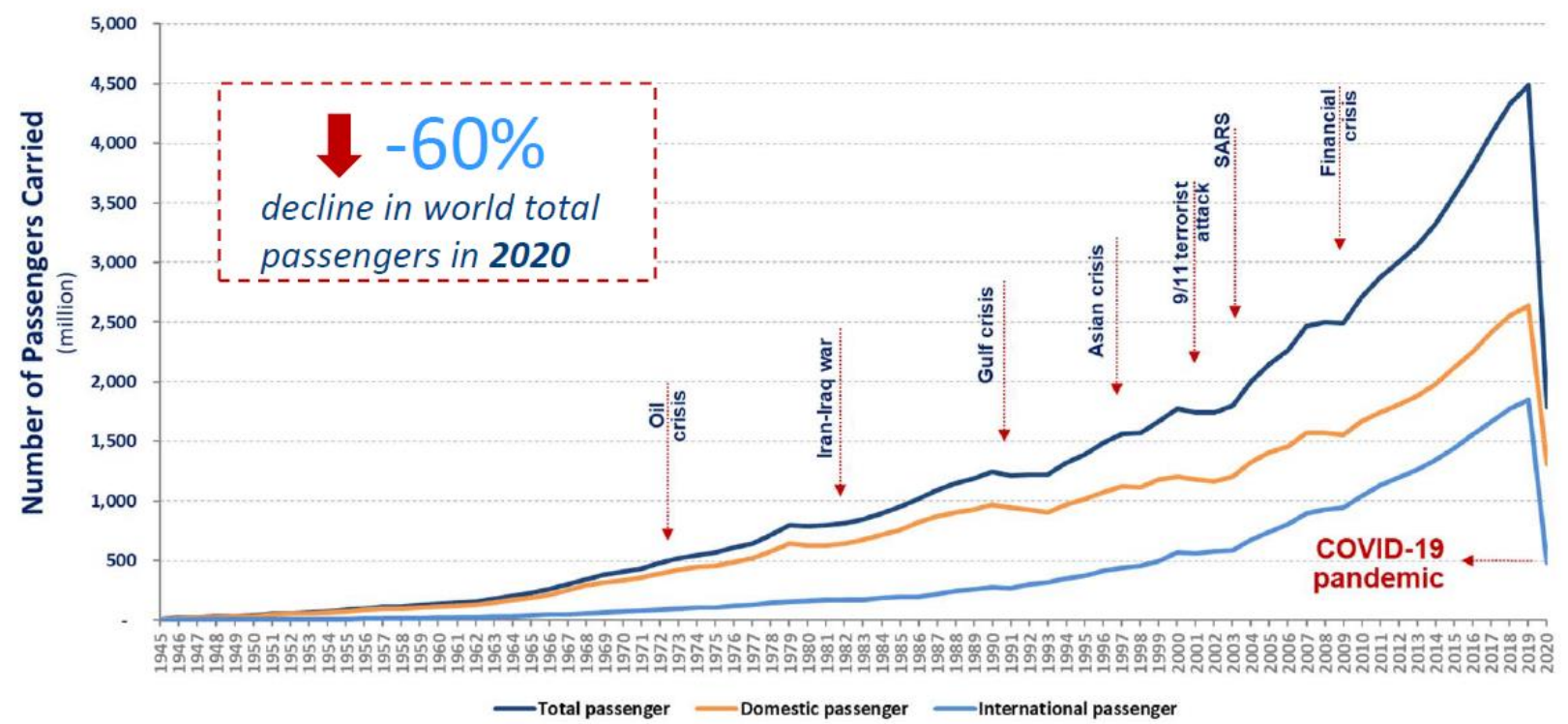

Figure 1 World Passenger Traffic Evolution and the Notable Decrease in Air Traffic from 1945 to 2020

Note: Adapted from "Effects of Novel Coronavirus (COVID-19) on Civil Aviation: Economic Impact Analysis" [9].

The World Health Organization (WHO) announced the first COVID-19 infected case in China on December 31, 2019 [10]. Outside China, the first infected case was reported by Thailand on January 13th and by Italy on February 21st [10]. The World Health Organization declared COVID-19 as a global pandemic outbreak on 11th March 2020 [11]. As there is no official medical treatment for the disease, governments around the world prohibited cross-country transportation. Most of the countries implemented strict public health measures to reduce the spread of COVID-19. These measures affected the airline industry seriously [12]. To flatten the curve of coronavirus infection, countries like China, Australia, New Zealand, and South Korea adopted an economic shutdown strategy [13, 14, 15]. The U.S recorded the largest number of cases by June 2020 with more than two million people infected with COVID-19 and countries like Brazil, Russia, United Kingdom, Spain, India, and Italy trailed behind, each with cases ranging from 200,000 to 775,000 cases [16].

The International Air Transport Association's (IATA) report estimated that the revenue passenger kilometers (RPK) will drop by $38 \%$ in 2020 compared to 2019 [17]. ICAO reported that there was an overall reduction of $50 \%$ of seats offered by airlines, which translates to reduction of 2,699 million passengers, and approximately USD 371 billion loss of gross passenger operating revenues of airlines [9]. The world passenger traffic collapsed to an exceptional $-60 \%$ decline in 2020 [9]. As the value of the airline industry decreased to an unprecedented level, it motivated this study to analyze the impact of COVID-19 on the performance of the airline industry during this period and how to prepare it for the Post-COVID-19 era.

\section{Research Methodology}

An online literature search was carried out using Google Scholar, Science Direct, Hunt Library of Embry-Riddle Aeronautical University, and Web of Science. The proper data associated with the strategy adopted by airlines for their success and the impact of COVID-19 on air transport were collected. The search was limited to articles that were published between 2000 and 2021. These online search engines were used to collect, review and synthesize primary and secondary data to obtain reliable information from credible sources like peer-reviewed research publications, 
industry reports, periodicals, websites, and news articles. The scientific articles related to the topic were selected and the new knowledge is combined with existing one which comes from academic research to extract useful findings.

\subsection{Data Collection and Analysis}

The first part of this research study assesses the impact of COVID-19 on global air traffic, passenger traffic and revenues by region of operation, number of international passengers by region, and the number of domestic passenger traffic by route group. The data for this study were collected from January 2019 to December 2020 from the International Civil Aviation Organization (ICAO) database [9]. The Excel data analytics and Google analytics tool were used for data analysis and visualization.

\subsection{PEST Analysis}

The research strategy of the second part of this study is based on PEST analysis. To understand the success and impact of any organization at the international level it is important to analyze its strategic management and this can be done by adopting the PEST analysis [18]. PEST analysis is used to gauge external factors that could impact the profitability of an organization. It is a powerful tool for understanding the strategic risk and it examines the Political, Economic, Social, and Technological factors that affect an organization [18]. Political factors (P) refer to several forms of government interventions and political lobbying activities in an economy. Economic factors (E) talk about the macroeconomic conditions of the external environment but also include seasonal considerations. Social factors $(S)$ include social, cultural, and demographic factors of the external environment. Technological factors (T) include technological changes and related activities that affect the external environment [19]. This research study aims to help the global airline industry and prepare them for the Post-COVID-19 era by focusing on the application of data analytics, and by identifying the opportunities to develop a strategy for future threats.

\subsection{Research Questions}

The unexpected outbreak of COVID-19 is a challenge for all stakeholders in the aviation industry. The magnitude of the economic loss is huge that the industry has not come across anything similar to this before. The research questions that guides this study are "Did the global pandemic affected the regional air traffic, passenger traffic and revenues by region of operation, and by route group?" and "What proactive measures should be taken to prepare the airline industry for Post-COVID-19 era with special reference to data analytics technology?"

\section{Results and Discussion}

\subsection{Impact of COVID-19 on Global Flight Operations}

The impact of COVID-19 on air traffic based on the region of origin is illustrated in Fig.2. The air traffic was heavily affected in the Middle-East region with a $-57.35 \%$ reduction. It was followed by Africa (-53.56 \%), Europe (-52.61 \%), and Latin-America and the Caribbean (-48.4\%). In terms of the number of flight operations, the Asia-Pacific region was the most affected with 4,913, 303 fewer flights than in 2019 and was followed by Europe $(-4,766,279)$ and North America $(-3,211,278)$.

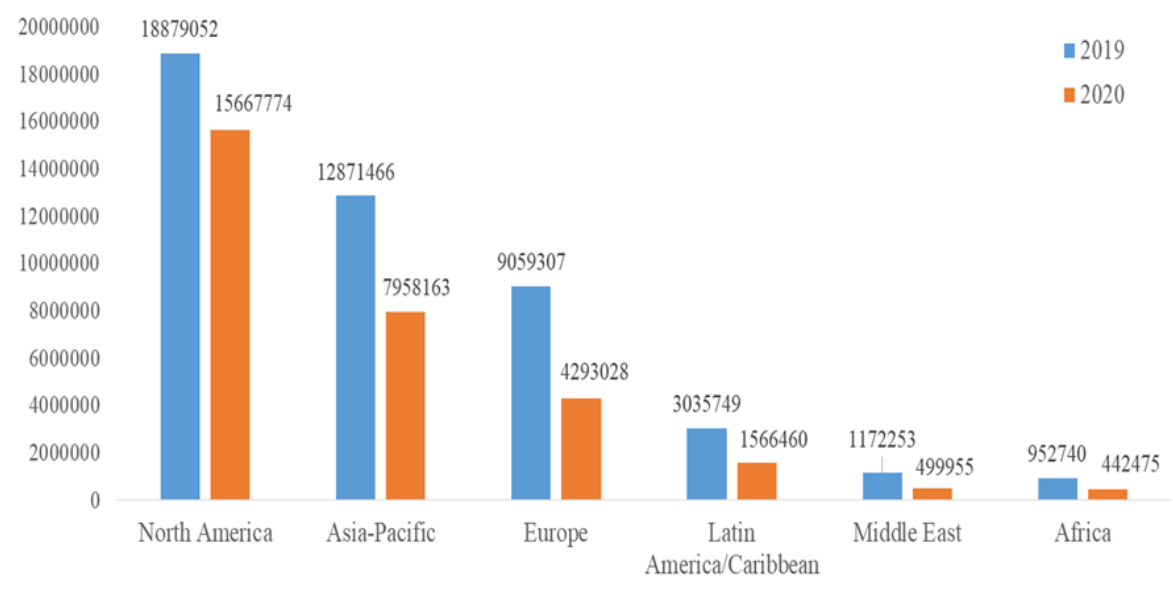

Figure 2 Impact of COVID-19 on Flight Operations at the Regional level, January 2019 to December 2020. 


\subsection{Impact of COVID-19 on Passenger Traffic and Revenues by Region}

As per the ICAO, the passenger traffic was low during the pandemic period. The estimated impact of COVID-19 on passenger traffic and revenues by region for the year 2020 is presented in Fig.3. The Asia-Pacific region was highly affected with negative 921 million passengers with 120 billion USD loss. This was followed by the European region with negative 769 million passengers causing a 100 billion USD loss, followed by the North American region with negative 599 million passengers which contributed to the loss of 88 billion USD in revenue. While Latin American/Caribbean was affected with negative 199 million passengers contributing to 26 billion USD loss, Middle East region with negative 132 million passengers led to 22 billion USD loss and African region with 78 million fewer passengers with USD 14 billion loss in revenue during 2020.

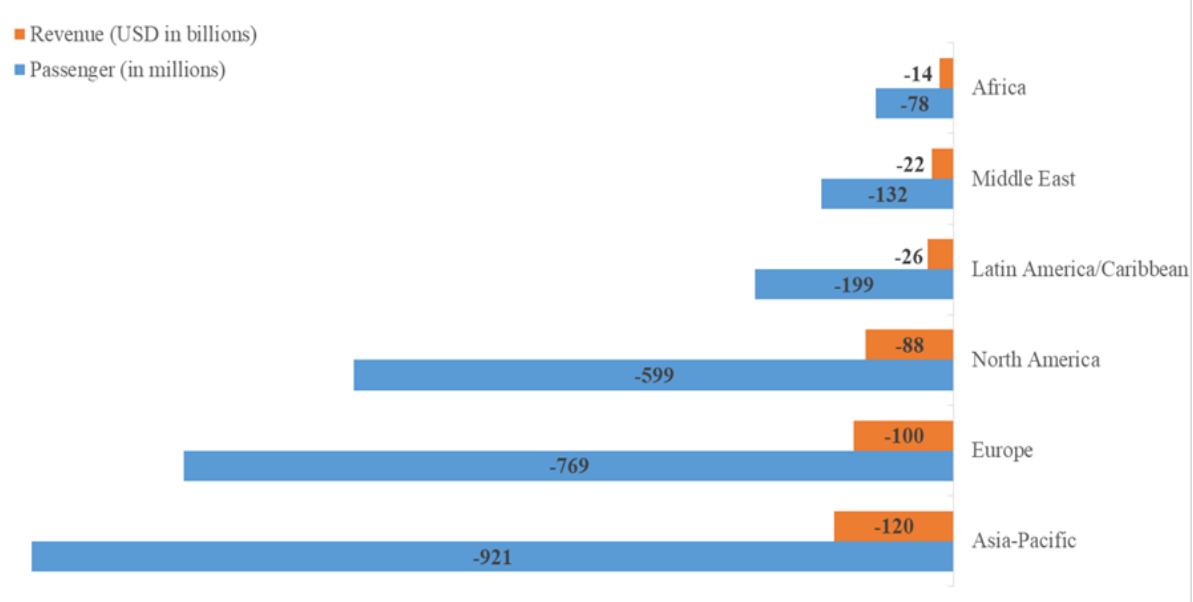

Figure 3 Impact of COVID-19 on Passenger Traffic and Revenues by Region for 2020 compared to 2019

\subsection{Effect of COVID-19 on International Passenger Traffic by Region}

In the year 2020, the pandemic affected the number of international passengers who traveled between different regions and it showed a sharp decrease when compared with 2019 passenger numbers of the same region (Fig.4). The European and Asia/Pacific region together accounted for around $70 \%$ of the world international traffic in 2020 . The rest of the travelers were from North America, Middle-East, Latin America/Caribbean, and Africa together contributed to $30 \%$.

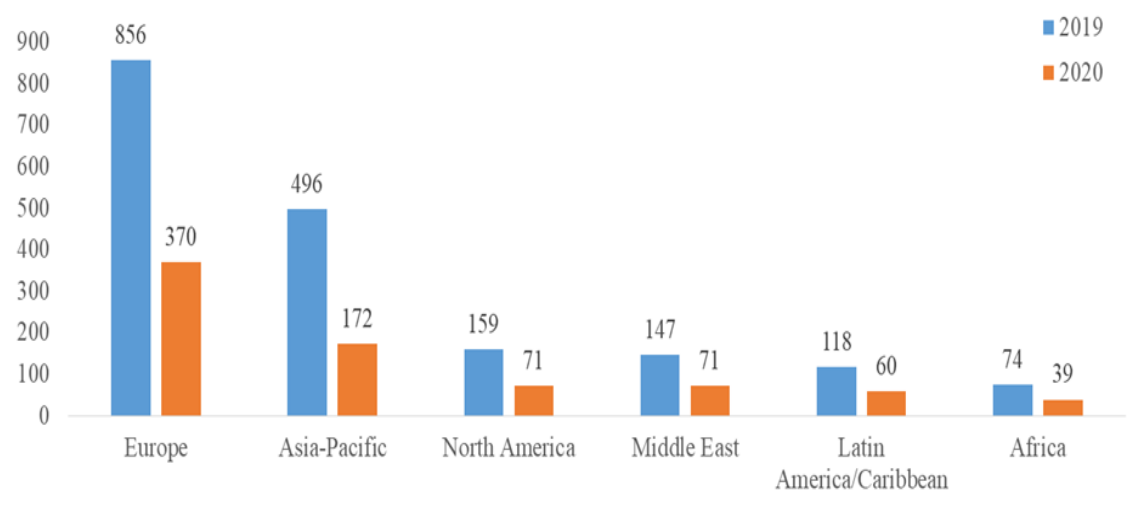

Figure 4 Number of International Passenger (in millions) by region (2019 vs 2020)

\subsection{Effect of COVID-19 on Domestic Passengers traffic by Route Group}

During the pandemic, the number of domestic passengers who traveled in specific route groups also exhibited a severe decline when compared with 2019 passenger numbers of the same route group (Fig.5). In 2020, China overtook North America with forty million more domestic passengers and the total number of domestic passengers in China accounted for 30\% of world domestic passengers. The third place was occupied by Europe with 159 million domestic passengers and it was followed by Pacific South East Asia (123 million), South America (75 million), South West Asia (73 million), North Asia (63 million), and the Central America/Caribbean (33 million). The lowest number of domestic passengers traveled in the African and Middle Eastern routes. 


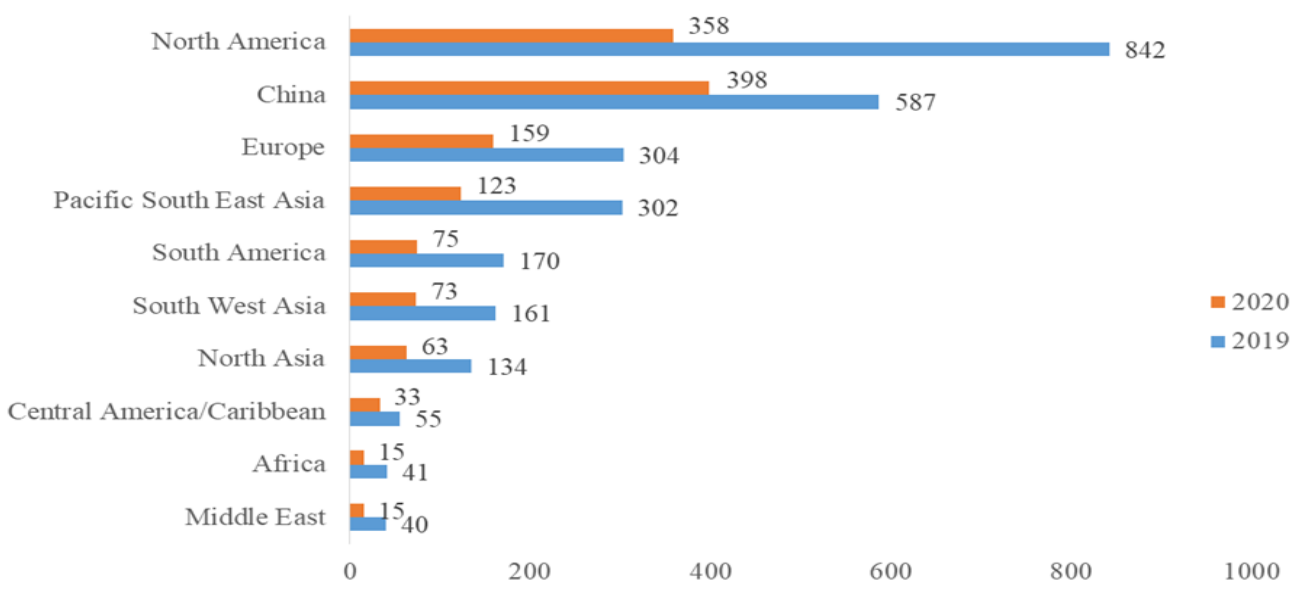

Figure 5 Number of Domestic Passengers in millions by Route Group (2019 vs 2020).

\subsection{PEST Analysis}

Most of the airlines around the world are facing serious economic set back due to increasing operating costs and deteriorating profits and margins which is caused by the global pandemic situation. PEST analysis was carried out to identify the factors that affect the global airline industry and the results are briefly discussed.

Political Factors - The COVID-19 occurrence had a huge effect on the airline industry. Most of the governments made harder restrictions to avoid the spread of coronavirus and some countries even changed the travel restrictions each day based on the number of COVID-19 cases. Governments are concerned about safety as the top priority for their citizens. Governments around the world offered economic support to airlines that are registered to operate within their airspace. In Europe, the airlines that received government support are Air-France ( 7 billion euros), Lufthansa airlines ( 9 billion euros), and British Airways (9.37 billion euros) [20]. The other airlines that received government support are EasyJet (600 million euros), Norwegian Air (12.7 billion euros), Ryanair (600 million euros), and Virgin Atlantic (500 million euros) [21].

The U.S. treasury department announced in April 2020 that Alaska Airlines, Allegiant Air, American Airlines, Delta Air Lines, Frontier Airlines, Hawaiian Airlines, JetBlue Airways, United Airlines, SkyWest Airlines, and Southwest Airlines would receive a bailout and the total amount was 25 billion USD and another 8 billion USD was allotted in grants and loans for cargo carriers [22]. This amount was mainly to support these airline companies to pay their workers. Governments and related regulatory organizations continued to focus on contingency and plan to prepare the airline industry to face the Post-COVID-19 era. The governments also adopted a temporary amendment to the rules on air services to support airlines and airports.

To overcome the pandemic crisis, Governments in association with other organizations like World Health Organization (WHO), International Civil Aviation Organization (ICAO), European Aviation Safety Agency (EASA), International Air Transport Association (IATA), Airports Council International Europe (ACI Europe), Eurocontrol and other related associations should start to cooperate to provide a healthy and sanitized environment for airline passengers and employees. While doing this, governments should also consider the data security and legal aspects of personal data [22].

Economic Factors - Due to the travel restrictions and border closures, the airline industry faces an economic disaster as the passenger number decreased. In Europe, the aviation industry lost 100 billion USD in revenue in 2020, while in the U.S the loss was estimated to be 88 billion USD, the Middle East region lost 22 billion USD, and the Asia-Pacific region lost 120 billion USD [9]. Regarding economic factors, airlines are recommended to work together with the governments and other organizations to provide healthy, sanitized travel and related services. They are recommended to reduce any unnecessary costs and possibly change their structure to surpass the losses. Airlines were allowed to change their target destinations and some airlines even changed to cargo flights for more profit.

Specifically, in the U.S., the approach of cargo only flights was tried out by Delta, United, and American airlines in 2020. These cargo flights mainly transported personal protective equipment and other medical-related items at the start of the pandemic and slowly airlines started redeploying their aircraft to deliver electronics, produce, apparel, pharmaceuticals, and even fish like salmon [23]. In April 2020, Delta airlines expanded its cargo-only flights between 
the U.S and Asia to support the transport of medical supplies [24]. The cargo revenue of the United airlines during the third quarter soared to approximately $50 \%$ from a year earlier to $\$ 422$ million which accounted for $17 \%$ of sales. While the revenue from passenger travel decreased $84 \%$ to 1.64 billion in 2020 due to the COVID-19 pandemic [23]. Some small carriers are also finding ways to partner with legacy carriers to survive the pandemic situation. Virgin Atlantic increased its cargo-only flights in May 2020 and scheduled daily services to Brussels, Beijing, U.S., and India. Emirates Airlines scheduled its 85 Boeing 777 flights as freighters in addition to its existing eleven 777s freighters. In Europe, Finnair was the first airline to remove the economy-class seats from the cabin of A-330s to increase the cargo space. Lufthansa Technik has completed a temporary cargo conversion of an A380 for an unnamed customer under the EASA eight-month exception [25].

Social Factors - The association that exists between family members, friends, neighbors, co-workers, and other associates is referred to as a social relationship. The quality of this relationship is affected by the positive aspects like emotional support from others, and negative aspects like stress and conflict. Covid-19 pandemic reduced this social relationship due to travel restrictions. Due to social distancing and travel restrictions, families and friends stayed apart which caused severe disappointment. Most of the countries tried to reduce or even eradicate contact between people in public places by implementing curfew through regulations. Though these measures are intended to protect people from the infection, they caused negative impacts like an increase in stress, loneliness, and domestic violence among the whole population [26, 27]. Among these negative impacts, loneliness and social isolation intensify stress and often caused negative effects on the mental, cardiovascular, and immune health of a person [28].

The economic loss of the airlines during the pandemic is attributed to (i) decrease in customer demand, changes in bookings, cancellations, and refunds due to travel restrictions and personal choice (ii) rise of operational cost due to maintenance requirements, available seats, costs from new health rules like cleaning and disinfecting of the cabin and (iii) change in financial status due to existing and new facilities, contracts, etc. The airlines tried to manage and reduce their operating costs by requesting their employees to volunteer for furloughs, lay-offs, deferring either engine or aircraft maintenance or both, and canceling the purchase orders to preserve liquidity [29]. In the U.S., the aircraft manufacturer Boeing decided to reduce its workforce by 10 percent, Delta Airlines furloughed 1941 pilots in October 2020, United Airlines furloughed 13,000 staff by October 2020, American Airlines announced it is furloughing 19,000 employees by October 2020, and Spirit Airlines decided to furlough 20-30\% of its workforce mainly pilots and flight attendants according to a July 28 internal memo [30].

Singapore Airlines announced that it is reducing its workforce by 20 percent that accounted for approximately 4300 jobs [31]. Emirates, the Middle Eastern Airlines announced it is set to cut 9000 jobs due to the pandemic [32]. British Airways, EasyJet, Ryanair, and Air France announced that they had to cut 12,000, 4500, 3000, and 7500 jobs respectively due to the pandemic [33]. This unemployment situation had a severe impact on the social life of people around the world. The jobless condition left the staffs in a situation that they were unable to meet their obligations and their emotion included all stages of grief from shock, denial, anger, bargaining, or even worse like committing suicide [34].

Governments and non-profit social organizations were recommended to help people and families. Government, employers, and non-profit organizations should provide educational campaigns to improve the social health and general wellness of the population. They should also inform the people regarding the up-to-date alternative communication media that are available. This would lead to effective communication and enable people to cope better with the pandemic and maintain societal well-being and productivity. Socializing is a vital necessity for humans and social distancing deters it, which ultimately affects their mental wellbeing [34]. While the social distancing may appropriately be enforced when required, the social aspect of human relationships must be strengthened to sustain their bonds and support the most vulnerable among them. So, aviation service providers must ensure that physical distancing of six feet is maintained wherever this is operationally feasible.

Technological Factors - It is important to identify the super spreaders and downstream contacts to control the spread of coronavirus among the general population. Google and Apple both worked on a smartphone-based approach but it was not realistic [35]. The contact tracing technology included Smartphone technology with sensors, external RFID and Bluetooth, video analytics tracking, and access control. The video systems were found to be more successful for thermal screening, video-based contact tracing, automated facemask detection, social distancing analytics and "hot-spot" detection, and occupancy sensing and threshold enforcement [35].

Airlines and airports around the world tried to get the latest technology in place to keep the aircraft cabins and airports disinfected and sanitized. Some of the major airports like Singapore Changi airport and London Heathrow Airport deployed Robots to serve their customers instead of employees for the sake of everyone's safety since Coronavirus became a pandemic [36]. Singapore Changi Airport deployed automated cleaning robots that also disinfected the surface 
after the cleaning process is over, and they also use Ultraviolet-C light technology to disinfect handrails on escalators and travelators. Changi airport also installed proximity touch screens at kiosks and infrared sensors to track finger movements to ensure people are not touching the screen and elevators were fitted with infrared technology that allowed passengers to get to the desired floor by hovering their hand over the sensor. In Malaysia, Air Asia introduced contactless kiosks and contactless payment options, in May 2020, at airports where it operates in Malaysia, Thailand, the Philippines, Indonesia, and Japan. This allowed passengers to check-in and make payments without actually touching the systems [37]. Self-check-in machines at Dubai International Airport are now touchless. Passengers using the 16 check-in kiosks can control the apparatus using a mobile device to scan a QR code displayed. The passenger can then check-in, receive their boarding pass, choose seats, and drop their bag without touching the screen.

To assess travelers' temperature, the staff of Doha International Airport wore thermal screening helmets which used infrared thermal imaging, artificial intelligence, and AR (augmented reality) display. Hong Kong International Airport deployed Intelligent Sterilization Robots (ISR) that are equipped with a UV light sterilizer and an air sterilizer to kill germs. At JFK International airport, an artificial intelligence platform called SafeDistance was employed to quickly identify overcrowded areas and open up other avenues of access in response [37]. Airports started to focus on "biometrics, touchless travel and self-service passenger check-in, smart restrooms, air quality improvements, maintaining social distancing requirements, enforcing mask-wearing to prevent spread, and enhanced cleaning procedures" [35]. Airlines and airports have to be proactive by focusing on new technologies and adopting operational changes to restore passenger confidence and reshape air travel and enhance the capabilities in the future.

\subsection{Application of Big Data Analytics in Aviation Industry}

The International Air Transportation Association (IATA) reported that the 2010-2019 decade was areat time for the airline industry and 2019 was the most profitable year with a net profit of 35.5 billion [38]. But due to the outbreak of COVID-19, the aviation industry was affected to an unprecedented level in 2020 with USD 371 billion loss of gross passenger operating revenues [9] and as a whole the aviation industry is facing major challenges. To face the pandemic, the aviation industry has to introduce digital transformation projects by investing in new technologies as it brings new opportunities. Big data analytics is one of the important emerging technology which is based on a simple concept such as data collection and analysis. Data analysis is essential to understand the problem that an organization faces. Data analytics helps to explore data in meaningful ways, organize, interpret, and presents the data into useful information that provides context for the data [39]. Data analytics can help intelligent, knowledgeable, and experienced people to make better decisions. Big data has the potential to create a competitive advantage when it is used properly and strategically [40].

Big Data Analytics (BDA) is defined as a "holistic approach to managing, processing and analyzing the $5 \mathrm{~V}$ data-related dimensions (i.e., volume, variety, velocity, veracity, and value) to create actionable ideas for delivering sustained value, measuring performance, and establishing competitive advantages" [41, p.356). BDA will help to ensure whether the airline industry is on the right track, will help to face the challenges, solve them quickly, and learn how to improve the current performance level. Lepenioti, Bousdekis, Apostolou, \& Mentzas [42] classified business analytics (BA) into three types based on the different levels of difficulty, value, and intelligence. They are descriptive, predictive, and prescriptive analytics. Using technology and descriptive analytics, the industry can gain insights from historical data and apply diagnostic analytics to identify the risk factors. They can utilize predictive analytics to conduct forecasting and employ the prescriptive analytics method to support data-driven decision-making. This holistic approach will help organizations and individuals to be competitive in the global market.

The duration of global recovery is highly uncertain as different countries might reopen at different times with various restrictions and precautionary measures based on their recovery level [43]. With the development of vaccines, normalcy might return soon and the economy might bounce back. But to succeed in the Post-COVID-19 era, the aviation industry has to embrace a higher level of collaboration and partnership. Singapore Airlines (SIA) has started trials on a new digital health verification process, which will be the first in the world to be based on the International Air Transport Association's (IATA) Travel Pass framework. This will offer customers the ability to securely store and present information related to Covid-19 tests, as well as their vaccination status in the future. It might require "a new level of cooperation across airlines, airports, air navigation organizations, partners, security agencies, support services, commercial and retail services, regulators, and customers" [44, p.3). To recover and prepare itself for the post-pandemic era, the aviation industry has to develop new strategies regarding "collection and sharing of data, more investment in the digital technologies, and might require agility, flexibility, and innovative thinking in every area of the business" [44, p.3]. 


\section{Recommendations based on Data Analytics Technology in Preparing Airlines for Post-Covid-19 Era}

\subsection{COVID-19 Airline Recovery Plan}

Global airlines can use big data analytics to develop an effective and efficient COVID-19 recovery plan. To recover and prepare for the Post-COVID-19 era, data analysis has to be done to identify the opportunities by following the steps described below. They are (i) tracking the COVID-19 progress and recovery at a global-scale analysis, regional and subregional analysis, and country analysis (ii) flight demand analysis by identifying the air route for reactivation (iii) tracking the demand for global air travel and (iv) customer-specific air travel demand tracking [45].

\subsubsection{Tracking the COVID-19 Progress and Recovery}

The World Health Organization's COVID-19 Dashboard showcases the global-scale analysis of the coronavirus progress in the world from the start of the outbreak up until today March 15, 2021 [46]. It specifies that the whole world is still heavily impacted by the COVID-19. After analyzing the global-scale progress and recovery of the COVID-19, airlines have to understand the regional-scale progress and recovery. The regional level data analysis of COVID-19 was provided in Fig.6. This will help to identify which regions of the world are performing better in terms of recovery. Based on this data, airlines can anticipate resuming air-travel to the countries in the Western Pacific, African, Eastern Mediterranean, and South-East Asian regions as they are progressing faster than the remaining regions of the world. Based on the WHO's dashboard airlines can identify the COVID-19 recovery at both the sub-regional level and country-level and plan appropriately to resume their operation in those regions were the recovery is faster than other regions.

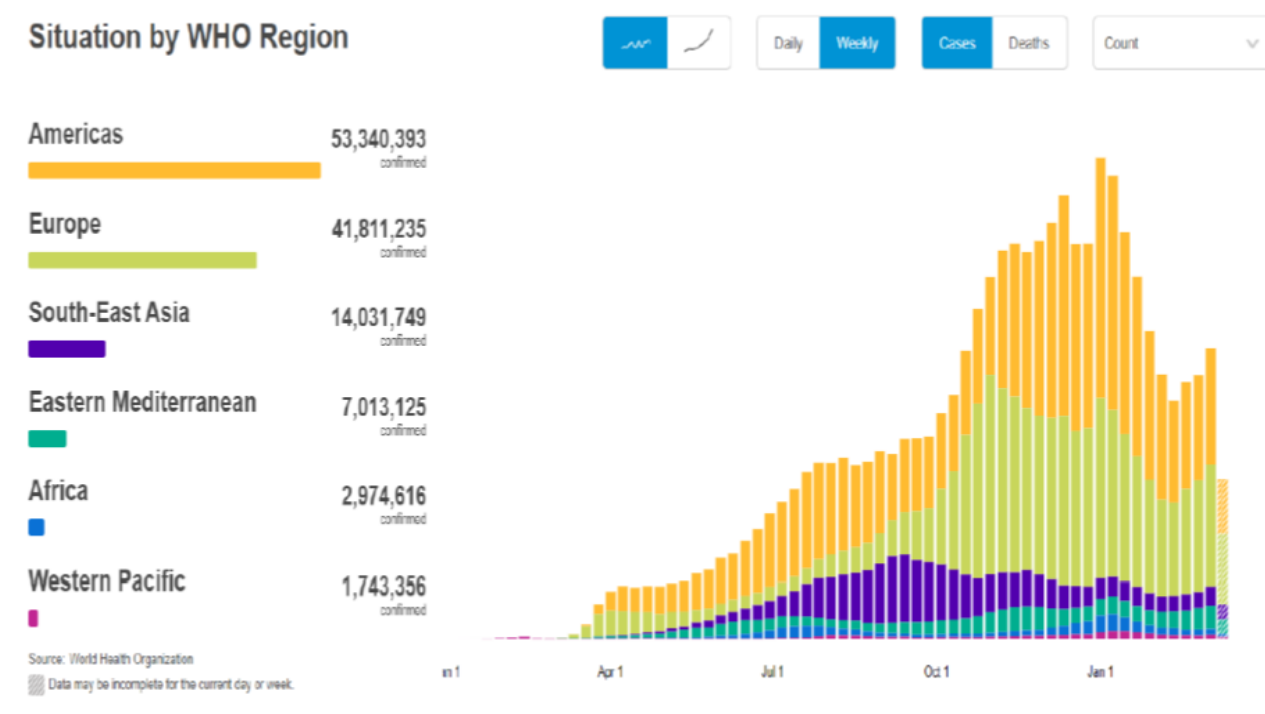

Figure 6 COVID-19 Data Analysis from the World Health Organization Dashboard from December 30, 2019 to March 15,2021

Note: Adapted from the WHO Coronavirus Dashboard [46].

\subsubsection{Flight Demand Analysis by Identifying the Air-route for Reactivation}

After comparing the recovery progress of each country and region against one another, airlines should identify the regions and countries where they can reactivate their operation. Airlines should then identify the flight demand for each route. Initially, due to the recession caused by the global pandemic, the demand will be naturally low and they should be cautious in re-activating the air-routes. Airlines should start their operation in the routes that are most in-demand first as that will be the most profitable way during this recovery phase and not all routes at once. In a recent study, data analysts compared six countries namely Iceland, Japan, South Korea, the US, Italy, and Germany. In comparison, this study identified that South Korea and Iceland are on track with effective containment (Fig.7) and airlines can expect to reactivate the routes between these two countries earlier than other countries [45]. 


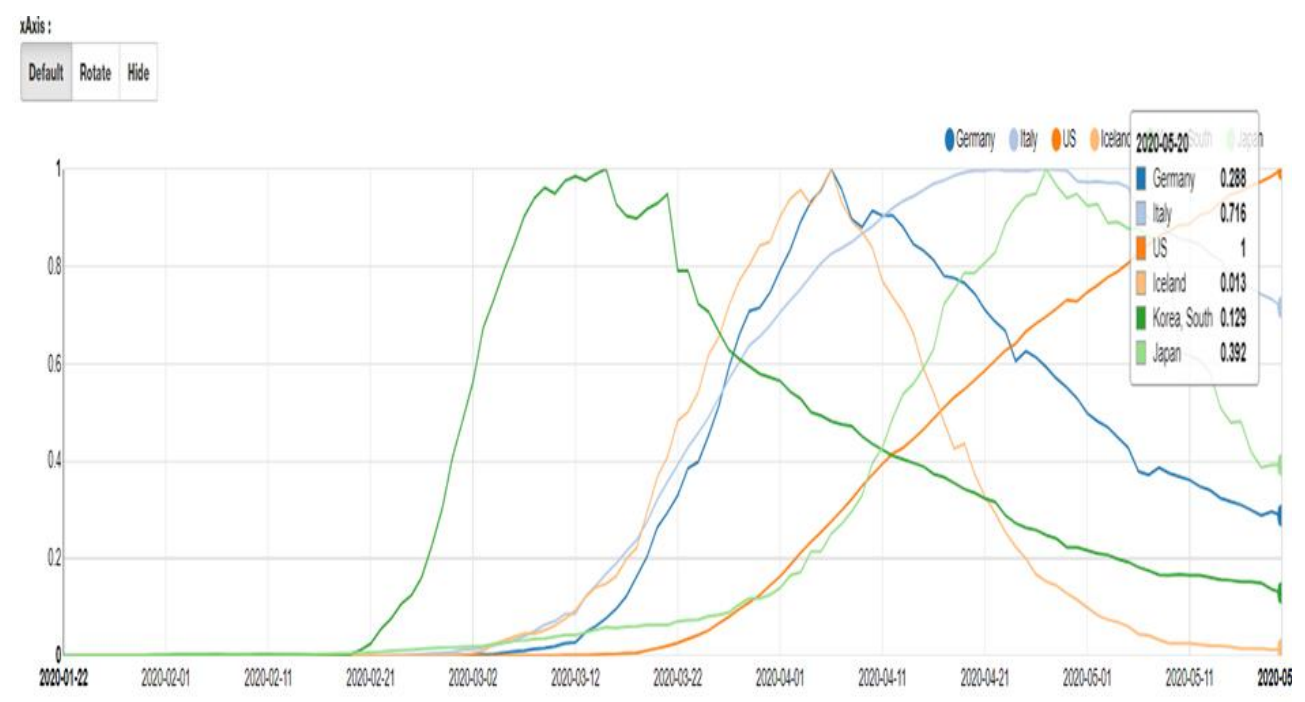

Figure 7 Country Status Comparative Analytics of the Coronavirus Impact

Note: Adopted from Big Data Analytics: The Solution for COVID-19 Airline Recovery [45].

\subsubsection{Tracking the Demand for Global Air Travel}

Once airlines have identified when and where their operation should be activated, they have to detect the demand level for cities and countries that people are looking to travel to. Then among those identified destinations airlines have to find which cities/countries have the highest level of demand. To illustrate the power of data, utilizing Google Analytics the following graph was prepared to find the flight demand from the United States to the four selected cities- London, Dubai, Toronto, and Tokyo from March 22, 2020 to March 20, 2021 (Fig.8).

As per this data analytics, it is visible how flight demand has continued to fall to all four destinations during the pandemic. The lowest demand for London was observed in November 2020 with 68 flights. But as of March 20, 2021, London has maintained to be the city with the highest flight demand with 86 flights. While during this one year the demand for Tokyo has fallen from fourteen flights to seven flights and is not safe to restart the operation in this route. For Dubai, the demand has increased from twenty-eight to thirty-eight. It is little safe to resume the operation in this air route. But in the case of Toronto, the highest demand was noticed from July 19 to 25, 2020 with forty-one flights and as of March 20, 2021the demand has dropped to 29. So if the airlines assume this route it will not be profitable. Once the countries open their borders and relax the quarantine periods, airlines can utilize this data analytics to determine the highest and lowest level of flight demand information and plan their air route. After properly planning the air route, they can direct their marketing, sales, and operational focus to promote these routes initially to recover and boost their sales.

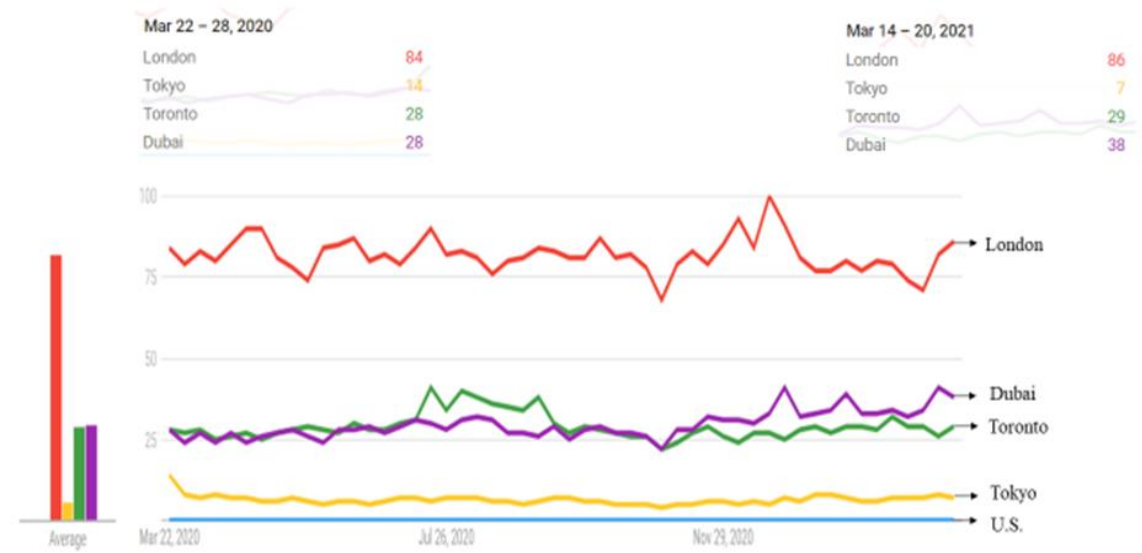

Figure 8 Google Flight Demand Analytics from the U.S. to four other countries from March 22, 2020 to March 20,2021 


\subsubsection{Customer-specific Air Travel Demand Tracking Using E-commerce}

E-commerce lets airlines have direct contact with their customers and gain data insights to personalize selling to individual customers' needs. The past customer behavior data and the strategies followed for marketing will be ineffective during this unprecedented period. An E-commerce centric strategy along with the data analytics of COVID19 will help airlines to recover from the impact of the global pandemic and prepare them for the new normal or PostCOVID-19 era [47]. To gain customers' attention and motivate travel, airlines have to embrace the data-driven personalized e-commerce strategy which includes identifying customer data, customer segmentation, and interacting with personalized promotions built on that specific data. The various functionalities of an e-commerce system like (a) user tracking (b) flexible analytics (c) real-time reactive analytics and (d) data science forecasting will be effective in identifying the customer-specific air traffic demand tracking [47]. User-tracking has to be activated for both purchasing and non-purchasing behavior as it is an important step in identifying the changing customer dynamics, and it provides important insights for tailoring personalized offers to attract customers back. The impact of COVID-19 is different for different countries. So, flexible big data analytics will help to get insights among various types of customers from different countries. Real-time reactive analytics will help to identify the customer behavior to fuel impulse purchases and secure hesitant buyers. Data science forecasting can be used to gain a competitive advantage as it would help the industry in the future to be better prepared to handle any unpredictable situations like this [47].

Airlines can utilize their e-commerce data in combination with other third-party data on the COVID-19 and social media to gain better insights in developing a strategic framework to prepare itself for the Post-COVID-19 era. This will help airlines to acquire data on the spread of COVID-19 and its variants, flight restrictions being imposed in other countries, customer sentiment, and other related factors and use predictive analytics to forecast losses accurately. This will allow airlines to see if they have enough cash to sustain the flights ahead of time and take realistic measures to bring down losses on these routes. Data analytics can also be used to predict and prepare for the outcomes of bookings and cancellations in real-time, and it will also provide insights to identify the specific geographic location to intervene and achieve maximum ROI (Return-on-Investment). An external consumer confidence index based on data will help airlines to measure the comfort level of the customers to start traveling again. Precise decision-making based on data analytics is essential and crucial for an effective Covid-19 airline recovery plan.

\subsection{Proactive Technology and Strategic Plan to Address COVID-19}

\subsubsection{Exceptional Collaboration}

COVID-19 has posed the greatest challenge to the global aviation industry by affecting its entire ecosystems - like airlines, airports, air navigation organizations, security agencies, support services, commercial and retail services, regulators, and customers [44]. As the world is expecting a recovery, the pandemic has indeed changed the way how businesses were done. Regarding the aviation industry, the demand is lower, there are new expectations and complex operational challenges [44]. To recover from this financial setback, the different stakeholders of the global aviation sector have to collaborate, cooperate and develop new partnerships that would enable the aviation industry to achieve operational agility that is required to protect the health and safety of both the passengers and their employees. They have to develop a route that would be more sustainable, commercial, profitable, and resistant to disruption and would have a growth potential in the Post COVID-19 era. Through a collaborative measure, different stakeholders of the aviation industry and third-party data providers should continue to share the data. They should invest more in digitalization to ensure that the industry emerges from the impact of the pandemic in a more responsive, agile, and financially sustainable way than ever before [44].

\subsubsection{Customer Care Initiatives}

Airlines and airports around the world should continue to invest in technologies to provide self-service capabilities that would allow passengers to cancel, re-schedule, re-fund their tickets without having to call customer service. This will also reduce the call center volumes and decrease the operational costs. They should take proactive measures to rebuild customer confidence.

\subsubsection{Information and Training Department}

Airlines and airports need separate information and training department to educate their employees regarding how to handle customers during health-related emergencies, and provide up to date information across the world. 


\subsubsection{Additional Long-term Measures}

Airlines should also adopt long-term measures to protect the health and well-being of their passengers. They should create self-service facilities such as biometric-based kiosk check-ins and automated baggage handling. Airports should install thermal scanners at the airports that feed the information into the operational control center and create overall health intelligence of passengers and alerts the airport administration when required. Airlines can permanently install infrared cleaning tools for aircraft interiors and continue the work from home option for employees who are not working in the front end. To reduce the operational cost further in this regard airlines can use virtualization, cloud, and collaboration tools [48].

\subsubsection{New Concepts and Technologies}

Companies from different segments of the aviation industry have introduced new concepts and technologies to help the aviation industry to reduce the transmission of the virus. In June 2020, Honeywell Aerospace brought Dimer's Germ Falcon machine to commercial airline cabins as the Honeywell UV Cabin System through a partnership program to treat the air cabin in a short time. This system significantly reduces certain viruses and bacteria on airplane cabin surfaces. JetBlue was the first airline that is evaluating Honeywell's UV system for cabin disinfection and sanitization. Bombardier received "a patent in July 2020 for the use of specialized air quality sensors for monitoring cabin and cockpit air quality" [49, p.5]. Jamco Corp., the "supplier of the cabin interior and seating launched an initiative called "Project Blue Sky" that included the latest hygienic and touchless air cabin technologies, that improved disinfection technologies for cabin use. It also visualizes future seats that would self-disinfect using UV cabin lighting" [49, p.11]. GE Aviation introduced the "Health Application ID," that is using blockchain technology to embed passenger identity information, ticket information, and medical screening results into the boarding process in a highly secure environment. London Heathrow International Airport is evaluating thermal imaging technologies as an effort to reduce the risk of COVID-19 transmission [49]. Airports can deploy robots to serve their customers, use automated cleaning robots to disinfect the surface after the cleaning process is over and they can also use Ultraviolet-C light technology to disinfect handrails on escalators and travelators. At self-service kiosks, airports can install infrared sensors to track finger movements to ensure people are not touching the screen and fit infrared technology at the elevators especially to allow passengers to get to the desired floor by hovering their hand over the sensor [36].

\section{Future Research Direction}

Different sources such as flight performance monitoring systems, operational systems of airlines and airports, and social media platforms provide a huge amount of real-time data related to flight performance, flight information, airport conditions, air traffic conditions, ticket prices, passengers' comments, crew comments, weather, etc. The aviation industry has to use data science and analytics in crucial areas like flight demand analysis, flight delay prediction, air transport network management, revenue management, crisis management on airline overbooking, aviation demand forecasting for airport planning, smart maintenance, reducing their operational costs, risk management, performance measurements, and customer satisfaction. Airlines can also use machine learning for air traffic management in ground delay programs, and runway utilization prediction. In the air cargo industry, data analytics can be used in areas like optimization in emergency air logistics, aircraft routing with maintenance staffing, and assessment of air transport networks. Though research is going on in these areas and some aspects of these data analytics are implemented by few airlines, measures have to be taken for its widespread application and success of the airline industry.

To prepare for the Post-COVID-19 era, future research should try (i) to use descriptive and diagnostic analytics to analyze real-time data to monitor the situation and identify changes in markets and consumer behavior (ii) it should focus on predictive analytics to predict demand and future customer behavior (iii) research should also use 'people analytics' with descriptive and diagnostic approaches to know employees' needs and situations to stabilize current operations. Research should also be carried (i) to figure out whether predictive analytics can be used to plan for the return to the workplace, as well as employee wellbeing and resilience (ii) would descriptive and diagnostic analytics will be an effective way to assess the impact of contingent policies and (iii) whether predictive analytics can provide a better estimate regarding public perception and reaction to adjust to the new pandemic-related policies.

\section{Conclusion}

The aviation industry was not prepared for the impact of COVID-19 and was one of the worst affected industries across the globe. This research study investigated the impact of the pandemic on the global air traffic and revenue by the region of air travel operation, and how COVID-19 affected the number of international and domestic passenger in different route groups across the world. The findings revealed that the world passenger traffic declined negative $60 \%$ which is 
exceptional in the history of air travel. To better understand the impact of COVID-19 on international travel a detailed PEST analysis was done. The result suggested that the governments of different nations understood the risks of COVID19 and made tougher restrictions to avoid the spread of the coronavirus. As the economy of the airline industry decreased drastically most of the governments intervened and offered economic support to the airlines operating in their air space. The COVID-19 pandemic reduced the social relationship due to travel restrictions and social distancing. These measures were proposed to protect the people but they also had some negative impacts on the social life which in turn affected their health. Regarding technological factors, governments tried to identify the super-spreaders of the virus through contact tracing while airlines and airports used the latest technology to disinfect and sanitize the aircraft and airports. The present research also details how data analytics would help the airline industry during this global pandemic situation and presented potential clarifications for the outcomes.

This study suggests that the airline industry has to consider the political, economic, social, and technological aspects into consideration and keep airlines working to make its ecosystem as safe as possible. The governments should work in collaboration with other organizations to provide a healthy and sanitized environment for airline passengers and employees. Apart from providing economical support, they also need to work with other countries to restart air transportation especially for business travellers and students through travel bubbles or air bubbles or corona corridors. This will provide a quarantine-free entry for passengers of the agreed countries. This will help to boost the industry to some extent. On January 28, 2021, the EU Council established an air bubble with a few countries. Following EU Council, Germany formed a travel bubble with Australia, New Zealand, Singapore, South Korea, and Thailand. In the Asia-Pacific region, Australia and New Zealand have formed the Trans-Tasman Bubble that officially starts on April 2021. Mutual consideration is essential for travel bubbles. Considering this, India has established bilateral travel bubbles with other countries which allow the airlines of both the agreed nations to enjoy similar benefits. Though the nature of the travel bubble is bilateral, governments should also consider "Multi-lateral Agreements." Multi-national Institutions like the EU and ASEAN should be given exceptional consideration in this regard. Another approach is bilateral bubbles can be merged or expanded to multi-lateral travel bubbles. This will help the airline industry to recover and also provide some social support to the people.

Airlines should specifically make use of data analytics technology to ensure financial viability. The greater use of data and digital technologies must be an essential part of the airline industry's recovery and resilience planning. As the results of this study suggested airlines should develop a COVID-19 Airline Recovery Plan by tracking the COVID-19 progress and recovery at a global, regional, sub-regional, and country-level, conducting flight demand analysis by identifying the air route for reactivation, tracking the demand for global air travel and through e-commerce strategy. This needs strong coordination, cooperation, and effective communication between different data analytics teams (internal and external), between all the departments within airlines, and the stakeholders of the aviation industry. This is vital to manage the current unprecedented situation and prepare the airline industry for the Post-COVID-19 era. Moreover, as the pandemic is still ongoing and new variants like B-117, B-1351, and P-1 variants are emerging, the industry needs long-term business support for organizational success and its survival. So, it is important to transform the organization to adapt to the changes quickly which needs strong agile leadership.

\section{Compliance with ethical standards}

\section{Acknowledgments}

I would like to thank Professor Patricia Beck, Campus Director, Embry-Riddle Aeronautical University - Worldwide, Phoenix-Mesa Campus, Arizona, USA for her moral support, and encouragement during this global pandemic. I thank my husband and son for their support during this unprecedented time to carry out this research study.

\section{References}

[1] Fan D, Li Y, Liu W, Yue XG, Boustras G. Weaving public health and safety nets to respond the COVID-19 pandemic. Safety Science. 2021; 134: 105058.

[2] Mehta P. Aviation During and Post Pandemic COVID-19 - Impact and Strategies. SF Journal of Aviation and Aeronautical Science. 2020; 2(1): 10-13.

[3] Air Transport Action Group [ATAG]. Employment-Aviation Benefit.

[4] Glaesser D, Kester J, Paulose H, Alizadeh A, Valentin B. Global travel patterns: An overview. Journal of Travel Medicine. 2017; 24(4). 
[5] Tuite AR, Bhatia D, Moineddin R, Bogoch II, Watts AG, Khan K. Global trends in air travel: implications for connectivity and resilience to infectious disease threats. Journal of Travel Medicine. 2020; 27(4): 1-8.

[6] Sadi MA, Henderson JC. The Asian economic crisis and the aviation industry: Impacts and response strategies, Transport Reviews. 2000; 20(3): 347-367.

[7] Gillen D, Lall A. International transmission of shocks in the airline industry. Journal of Air Transport Management. 2003; 9(1): 37-49.

[8] Olaganathan R, Amihan RAH. Impact of COVID -19 on Pilot Proficiency - A Risk Analysis. Global Journal of Engineering and Technology Advances. 2021; 6(3): 001-013.

[9] ICAO. Effects of Novel Coronavirus (COVID-19) on Civil Aviation: Economic Impact Analysis. Report submitted to the Economic Development - Air Transport Bureau. 2021.

[10] World Health Organization (WHO). WHO Timeline - COVID-19. 2020.

[11] Dunford D, Dale B, Stylianou N, Lowther E, Ahmed M, Arenas IdlT. Coronavirus: The world in lockdown in maps and charts. 2020.

[12] Donthu N, Gustafsson A. Effects of COVID-19 on Business and Research. Journal of Business Research. 2020; 117: 284-289.

[13] Qiu, Yun, Xi Chen, Wei Shi. Impacts of social and economic factors on the transmission of coronavirus disease 2019 (COVID-19) in China. Journal of Population Economics. 2020; 33: 1127-72.

[14] Shaked Israel, Brad Orelowitz. The airline industry and COVID-19: Saving for a rainy day. American Bankruptcy Institute Journal. 2020; 39: 36-37, 57-58.

[15] Slater A. The economic cost of coronavirus lockdowns. Oxford Economics. 2020; 44: 17-19.

[16] Worldometer. COVID-19 Coronavirus Pandemic. 2020.

[17] Pearce B. IATA Economic Reports: COVID-19 Updated Impact Assessment of the Novel Coronavirus. 2020.

[18] Porter M. The Competitive Advantage: Creating and Sustaining Superior Performance. NY: Free Press. 1985.

[19] Sammut-Bonnici T, David G. PEST Analysis. Wiley Encyclopaedia of Management. American Cancer Society. 2015.

[20] Keating D. EU Airlines Seek €12.8bn In Bailouts. Forbes. 2020.

[21] Otley T. These airlines have received a bailout. Business Traveller. 2020.

[22] Rappeport A, Chokshi N. Crippled Airline Industry to Get \$25 Billion Bailout, Part of It as Loans. The New York Times. 2020.

[23] Josephs L. In pandemic travel bust, cargo shipments of Botox and cheese replace passengers for starving airlines. 2020.

[24] Delta News Hub. Delta expands to daily cargo-only flights between U.S. and Asia. 2020.

[25] Morrison M. How coronavirus has turned the airfreight market on its head. Air Cargo News. 2020.

[26] Algunmeeyn A, El-Dahiyat F, Altakhineh MM, Azab M, Babar ZUD. Understanding the factors influencing healthcare providers' burnout during the outbreak of COVID-19 in Jordanian hospitals. Journal of Pharmaceutical Policy and Practice. 2020; 13(1): 1-8.

[27] Piquero AR, Riddell JR, Bishopp SA, Narvey C, Reid JA, Piquero NL. Staying home, staying safe? A short-term analysis of COVID-19 on Dallas domestic violence. American Journal of Criminal Justice. 2020; 45: 601-635.

[28] Hawkley LC, Cacioppo JT. Loneliness matters: A theoretical and empirical review of consequences and mechanisms. Annals of Behavioral Medicine. 2010; 40(2): 218-227.

[29] Ramsey M. Airlines and Covid-19. 2020.

[30] Borden T, Akhtar A, Hadden J, Bose D. The coronavirus outbreak has triggered unprecedented mass layoffs and furloughs. Here are the major companies that have announced they are downsizing their workforces. Business Insider. 2020.

[31] Freed J. Singapore Airlines to cut 4,300 jobs due to pandemic, most in its history. 2020.

[32] Josephs J. Coronavirus: Emirates set to cut 9,000 jobs, citing pandemic. BBC News. 2020. 
[33] Davies P, Tidey A. Coronavirus job cuts: Which companies in Europe are slashing their workforces because of COVID-19? EuroNews. 2020.

[34] Nicola M, Alsafi Z, Sohrabi C, Kerwan A, Al-Jabir A, Iosifidis C, Agha M, Agha R. The socio-economic implications of the coronavirus pandemic (COVID-19): A review. International journal of surgery (London, England). 2020; 78: 185-193.

[35] Varwig Z. Contact Tracing and COVID-19 Technology Best Practices. Aviation Pros. 2020.

[36] Chung-En Y. Humanlike Robots as Employees in the Hotel Industry: Thematic Content Analysis of Online Reviews. Journal of Hospitality Marketing \& Management. 2020; 29(1): 22-38.

[37] Preetipadma. How Is Singapore Armoring Up to Covid-19 at its Airports? Analytics Insights.

[38] Feliu C. Big Data in the Airline Industry: 5 Case Studies from the industry leaders. White Paper Prepared for Datumize. 2020.

[39] Gavin M. Business Analytics: What It Is \& Why It's Important? Harvard Business School. 2019.

[40] Singh SK, El-Kassar A. Role of big data analytics in developing sustainable capabilities. Journal of Cleaner Production. 2019; 213: 1264-1273.

[41] Wamba SF, Gunasekaran A, Akter S, Ren SJ, Dubey R, Childe SJ. Big data analytics and firm performance: Effects of dynamic capabilities. Journal of Business Research. 2017; 70: 356-365.

[42] Lepenioti K, Bousdekis A, Apostolou D, Mentzas G. Prescriptive analytics: Literature review and research challenges. International Journal of Information Management. 2020; 50: 57-70.

[43] Chung S, Ma H, Hansen M, Choi T. Data science and analytics in aviation. Transportation Research. Part E, Logistics and Transportation Review. 2020; 134: 101837.

[44] Deloitte. COVID-19 - Aviation's Recovery Flight Plan - Preparing for the New Normal. 2020.

[45] Natasha. Big Data Analytics: The Solution for COVID-19 Airline Recovery. Iunera. 2021.

[46] World Health Organization [WHO]. WHO Coronavirus (COVID-19) Dashboard. 2021.

[47] Gasson S. The impact of E-commerce technology on the air travel industry. Journal of Cases on Information Technology. 2003; 5: 234-249.

[48] Saulat A. Proactive Technology Strategies for Airlines to Succeed Post COVID-19. Aviation Pros. 2021.

[49] Bellamy W. 10 New Concepts, Technologies Developed to Address COVID-19 in Aviation. Avionics International. 2020. 